\title{
Acupuncture Effects on Cerebral Blood Flow during Normoxia and Normobaric Hypoxia: Results from a Prospective Crossover Pilot Study
}

\author{
Oriana Pecchio ${ }^{1, \dagger}$, Massimo Martinelli ${ }^{2, *},+\infty \mathbb{D}$, Giuseppe Lupi ${ }^{1, \dagger}{ }^{,}$, Guido Giardini ${ }^{3}$, Laura Caligiana ${ }^{3}$, \\ Solange Bonin ${ }^{3}$, Marco Scalese ${ }^{4}$, Ovidio Salvetti ${ }^{2} \oplus$, Davide Moroni ${ }^{2}{ }^{-}$and Luca Bastiani ${ }^{4}$ \\ 1 Centro Studi Terapie Naturali e Fisiche, 10143 Torino, Italy; pecchiooriana@gmail.com (O.P.); \\ giuseppe-lupi@libero.it (G.L.) \\ 2 Signals \& Images Laboratory, CNR Institute of Information Science and Technologies, 56124 Pisa, Italy; \\ ovidio.salvetti@isti.cnr.it (O.S.); davide.moroni@isti.cnr.it (D.M.) \\ 3 High Specialization Centre in Mountain Medicine and Neurology, 11100 Aosta, Italy; \\ ggiardini@ausl.vda.it (G.G.); lcaligiana@ausl.vda.it (L.C.); sole81@libero.it (S.B.) \\ 4 CNR Clinical Physiology Institute, 56124 Pisa, Italy; scalese@ifc.cnr.it (M.S.); luca.bastiani@ifc.cnr.it (L.B.) \\ * Correspondence: massimo.martinelli@isti.cnr.it; Tel.: +39-050-621-2803 \\ + Share co-first authorship.
}

\section{check for}

updates

Citation: Pecchio, O.; Martinelli, M.; Lupi, G.; Giardini, G.; Caligiana, L.; Bonin, S.; Scalese, M.; Salvetti, O.;

Moroni, D.; Bastiani, L. Acupuncture Effects on Cerebral Blood Flow during Normoxia and Normobaric Hypoxia: Results from a Prospective Crossover Pilot Study. Technologies 2021, 9, 102. https://doi.org/ 10.3390/technologies 9040102

Academic Editor: Fabrizio Stasolla

Received: 4 November 2021

Accepted: 15 December 2021

Published: 20 December 2021

Publisher's Note: MDPI stays neutra with regard to jurisdictional claims in published maps and institutional affiliations.

Copyright: (c) 2021 by the authors. Licensee MDPI, Basel, Switzerland. This article is an open access article distributed under the terms and conditions of the Creative Commons Attribution (CC BY) license (https:/ / creativecommons.org/licenses/by/ $4.0 /)$.
Abstract: Cerebral blood flow (CBF) is significantly influenced by exposure to hypoxia, both hypobaric and normobaric. Alterations in cerebral blood flow can play a crucial role in the pathogenesis of acute mountain sickness (AMS) and its symptoms, especially headache, dizziness, and nausea. Acupuncture has been proven to be effective in treating some cerebrovascular disorders and PC6 Nei Guan stimulation seems to enhance cerebral blood flow. Therefore, we have hypothesized that PC6 Nei Guan stimulation could affect CBF in acute hypoxia and could be used to contrast AMS symptoms. We evaluated blood flow in the middle cerebral artery (MCA) in normoxia, after $15 \mathrm{~min}$ in normobaric hypoxia (fraction of inspired oxygen $\left(\mathrm{FiO}_{2}\right) 14 \%$, corresponding to $3600 \mathrm{~m}$ a.s.l.) in basal conditions, and after PC6 Nei Guan stimulation, both by needle and by pressure. No comparisons with other acupuncture points and sham acupuncture were done. PC6 stimulation seemed to counteract the effects of acute normobaric hypoxia on end-diastolic velocity (EDV) in MCA, especially after acupuncture, and significantly reduced systolic and diastolic blood pressure. A rebalance of CBF could control some AMS symptoms, but further studies are necessary.

Keywords: PC6 Nei Guan stimulation; cerebral blood flow; hypoxia; pilot study

\section{Introduction}

\subsection{Cerebral Blood Flow in Hypoxia}

$\mathrm{CBF}$ regulation is a complex mechanism, significantly influenced by exposure to high altitude hypoxia. Alterations in CBF, brain volume, and intracranial pressure can play a crucial role in the pathogenesis of AMS - especially in headache and dizziness [1].

It is well documented that CBF increases in response to the severity of hypoxic stimuli in humans via cerebral vasodilation [2-4].

As observed by Berré, breathing a hypoxic mixture (i.e., with $\mathrm{FiO}_{2}$ equal to $12.5 \%$ ) for fifteen minutes causes an increase in flow velocity in the middle cerebral artery (MCA), both in subjects with a history of pulmonary oedema at high altitudes, in normal controls, and in elite climbers who tolerate high altitudes well [5].

Baumgartner found that the flow velocity in the MCA, after a rapid climb to $4559 \mathrm{~m}$, increased significantly over the next twenty-four hours, and remained elevated for fortyeight hours. The increase was higher in subjects with symptoms of acute mountain sickness than in asymptomatic volunteers and was directly correlated with arterial $\mathrm{PO}_{2}[6]$. 
Nevertheless, repeating the measurements of MCA flow in subjects in a hypobaric chamber-at a simulated altitude of $4500 \mathrm{~m}$-after twelve minutes, three hours, and six hours, Baumgartner no longer observed either uniformity in the changes of flow velocity, nor any correlation with symptoms of AMS. He underlined the remarkable inter-individual differences in CBF [7].

As emphasized by Brugniaux, acute exposure to high altitudes produces an increase in $\mathrm{CBF}$ related to the severity of hypoxia and of hypocapnia secondary to hyperventilation [8]. Lucas observed an increase in flow velocity in the MCA upon arrival at $5000 \mathrm{~m}$ - even at rest. These elevations were strongly correlated with changes in the $\mathrm{PaO}_{2} / \mathrm{PaCO}_{2}$ ratio [9].

Arterial blood flow velocity increases in all brain regions after a rapid ascent to $3700 \mathrm{~m}$, as seen by Bian in a large sample of young Chinese people suffering from AMS. Symptoms specifically correlated with increases in diastolic flow velocity, as well as decreases in the resistance and pulsatility indices of the basilar artery and of the general posterior cerebral circulation [10].

As hypothesized by Sagoo, there is a possible link between hypoxia, increased arterial inflow, a hypothetical rise in Starling pressure, and the subsequent development of clinical signs of AMS, and later of brain oedema [11].

AMS can occur after staying a few hours at high altitudes (more than $2500 \mathrm{~m}$ ), and it is favoured by a rapid ascent [12]. AMS can be diagnosed, using the Lake Louise questionnaire, by the presence of headache plus at least one of the following symptoms: gastrointestinal disorders (nausea and vomiting), fatigue or weakness, and dizziness or light-headedness-rated from 0 to 3 , for a total score $\geq 3$, in the presence of a recent ascent to high altitudes [13].

\subsection{Mechanism of Action of Acupuncture}

Acupuncture is a therapeutic technique that is part of traditional Chinese medicine (TCM). According to TCM, acupuncture is believed to restore the balance between Yin and Yang (opposite, complementary, interdependent and mutually consuming aspects of the universe and of the human body). All symptoms and signs are due, in the end, to an imbalance between Yin and Yang [14].

Manual acupuncture is defined as the insertion of a thin acupuncture needle at specific points on the body, called acupuncture points, followed by the twisting of the needle up and down by hand, to obtain the "De-Qi". In manual acupuncture, all types of afferent fibers $(\mathrm{A} \beta, \mathrm{A} \delta$ and $\mathrm{C})$ are activated [15].

Acupuncture's effects depend on the specific acupuncture point stimulation [16,17], on the patient's feeling after needle insertion and manipulation (a sort of combination of soreness, numbness, heaviness, and distension), the so-called "De-Qi", and on the "needle grasp" perceived by the acupuncturist [18].

Acupuncture has been proven to be effective in treating some cerebrovascular disorders [19-22] and a diminished blood flow velocity in the MCA after PC6 Nei Guan stimulation has been observed in normal subjects and in migraine patients [23]. Acupuncture effects on brain hemodynamic have been largely studied [24]. Moreover, it has been demonstrated that acupuncture's analgesic effects are carried out by interactions with the hypothalamic-pituitary-adrenal axis and the endogenous opioid system [25].

PC6 Nei Guan (Figure 1) is an important acupuncture point in the pericardium meridian of the hand. The location of PC6 Nei Guan is two "cun" (a cun is a measure equivalent to the width of the patient's thumb) above the transverse skin crease of the wrist, between the tendons of the palmaris longus and flexor carpi radialis muscles [26]. 


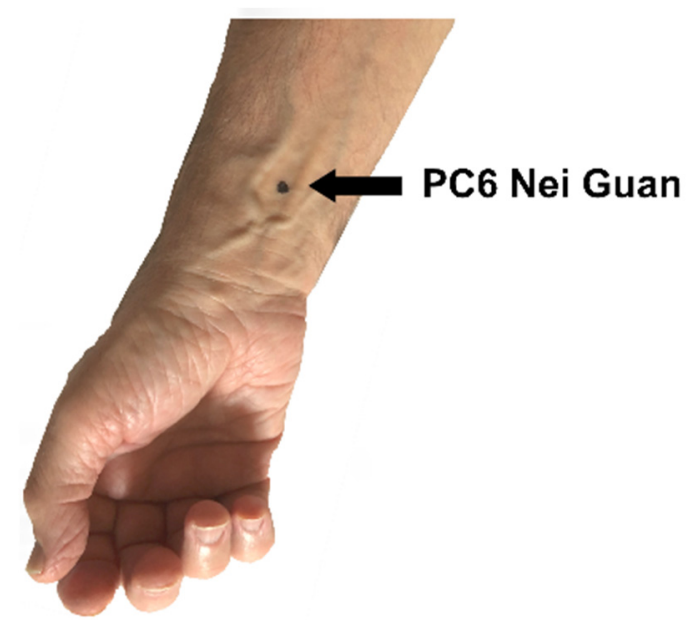

Figure 1. The location of PC6 Nei Guan.

TCM clinical indications for PC6 Nei Guan are related to the heart (chest pain, palpitations, and oppression), to gastric disturbances (gastric pain, nausea, and vomiting) and to neurological conditions such as anxiety, irritability, depression, and insomnia. Furthermore, it is used to treat breast tension and dysmenorrhea, and in abdominal surgical analgesia. It is also used as a local point in hand and wrist pain [26].

As seen by many studies, PC6 Nei Guan is largely used in the prevention and therapy of nausea and vomiting, in kinethopathy, chemotherapy, pregnancy, migraine and postoperative nausea and vomiting (PONV) [27]. A recent Cochrane systematic review states that there is no difference between PC6 acupoint stimulation and antiemetic drugs in the incidence of nausea, vomiting, and the need for a rescue antiemetic in PONV (moderate quality evidence) [28]. In addition, experimental data in rats with an occlusion of the right MCA show that electroacupuncture in LI11 Qu Chi and PC6 Nei Guan (in the arm contra-lateral to the ischemia), cause a significant increase in blood flow in the ischemic area-most likely based on neural-controlled regulation [22]. Another study in patients with and without migraine showed that PC6 Nei Guan stimulation increases CBF [23].

Stimulation of the PC6 Nei Guan point could therefore influence the CBF in acute hypoxia, and some AMS symptoms such as headache, nausea, weakness and dizzinesscommon to migraine-could also be treated by acupuncture $[29,30]$.

From the point of view of TCM, PC6 Nei Guan could counteract sleep disturbances, often seen in high altitude hypoxia, by its sedative action. Moreover, its action on nausea and vomiting - which are symptoms of AMS - allow for better hydration and nutrition, and it seems that a good hydration can reduce the risk of AMS [31].

PC6 Nei Guan stimulation is also possible through prolonged pressure, such as can be obtained with a specific elastic wristband commonly used in nausea caused by kinethopathy, during pregnancy, and after chemotherapy.

\subsection{Aim of the Study}

We hypothesized that PC6 stimulation could contrast the action of acute hypoxia on CBF and act on some symptoms of AMS. The aim of this study is therefore to evaluate the effects of PC6 stimulation - both with bilateral PC6 acupuncture, and after four hours of bilateral pressure using a wristband called a "sea band"—on the CBF in conditions of normoxia and acute normobaric hypoxia $\left(\mathrm{FiO}_{2}\right.$ equal to $14 \%$, corresponding to a simulated altitude of about $3600 \mathrm{~m}$ ) for $15 \mathrm{~min}$. Subjects were chosen with a history of acute mountain sickness, albeit mild, due to their supposed greater sensitivity to acute hypoxia, as previously seen.

Studying the response to PC6 stimulation in acute normobaric hypoxia could serve as a model for subjects suffering from pathologies in which hypoxemia is present. 


\section{Materials and Methods}

The study protocol was approved by the Ethics Committee of the Aosta Valley Medical Agency and all the subjects gave their informed consent for inclusion before their participation. Moreover, the study was conducted in accordance with the Declaration of Helsinki.

Seventeen subjects, aged between 18 and 50 years-old, BMI $>18$ and $<28$, who were not smokers, not in drug therapy, and who had previously experienced AMS symptoms, were enrolled.

This study was performed in a monocentric, controlled design; each subject at the enrollment was part of the control group. All the subjects underwent a cardiopulmonary rest test in normoxia, and then, after breathing a hypoxic mixture $\left(\mathrm{FiO}_{2} 14 \%\right)$ for $15 \mathrm{~min}$ using a Cosmed Quark PFT to measure heart rate (HR) and oxyhaemoglobin saturation $\left(\mathrm{SaO}_{2}\right)$. The hypoxic mixture was delivered by an AltiTrainer from SMTEC, a device for research in hypoxic conditions which enables adjustment of the $\mathrm{FiO}_{2}$ by up to $10.5 \%$.

After at least one week, all the subjects were randomized to one of two groups: the acupuncture (A) or the acupressure (B) group. All the tests were repeated under PC6 stimulation, and then in crossover, after a washout period lasting 10-14 days to eliminate the effects of the treatment (Figure 2).

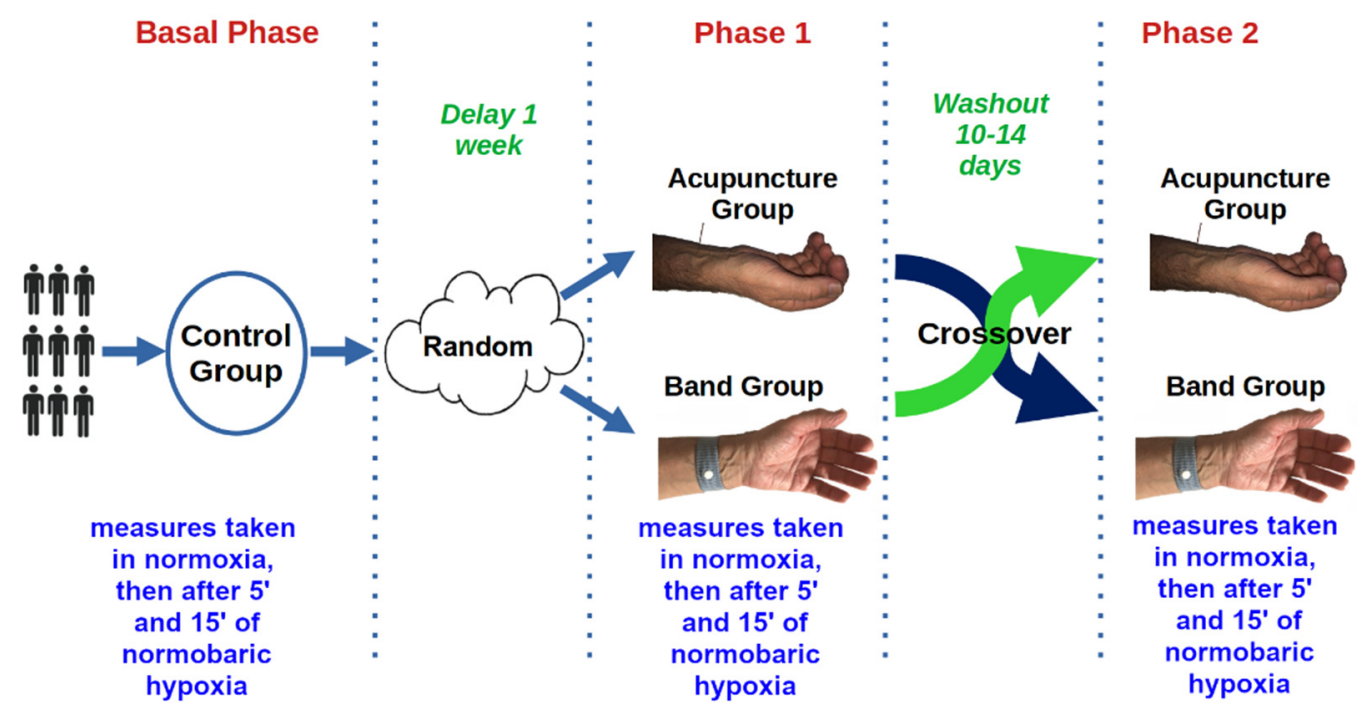

Figure 2. Main flow of the study.

Systolic and diastolic blood pressure (SBP and DBP) were measured at normoxia, and after 5 and 15 min of hypoxia, with a SunTech Tango M2 (Figure 3) automatic device, which also measured $\mathrm{SaO}_{2}$.

The CBF in the MCA was measured unilaterally (right or left) through the transtemporal window by transcranial echo-color doppler, using an ultrasound $\mathrm{M}$-Turbo Sonosite with a 1-5 Mhz multi-phase P21x probe. In the proximal tract of the MCA, peak systolic velocity (PSV) and end diastolic velocity (EDV) were measured. The pulsatility index (PI) and resistive index (RI) were calculated over an average of three cardiac cycles directly from the ultrasound device. All these measurements were done in basal conditions and after 5 and 15 min of hypoxia (Figure 3).

Acupuncture was performed using TeWa single-use, sterile, coated, acupuncture needles (Asia-med $\mathrm{GmbH}$ supplier), after skin cleaning with a 75\% alcohol swab. Acupuncture needles were inserted into the skin at PC6 acupoints bilaterally and stimulated to obtain the De-Qi sensation immediately before the test, and then left until the end of the test, when the two needles were carefully taken out and the puncture sites were compressed to avoid bleeding. 


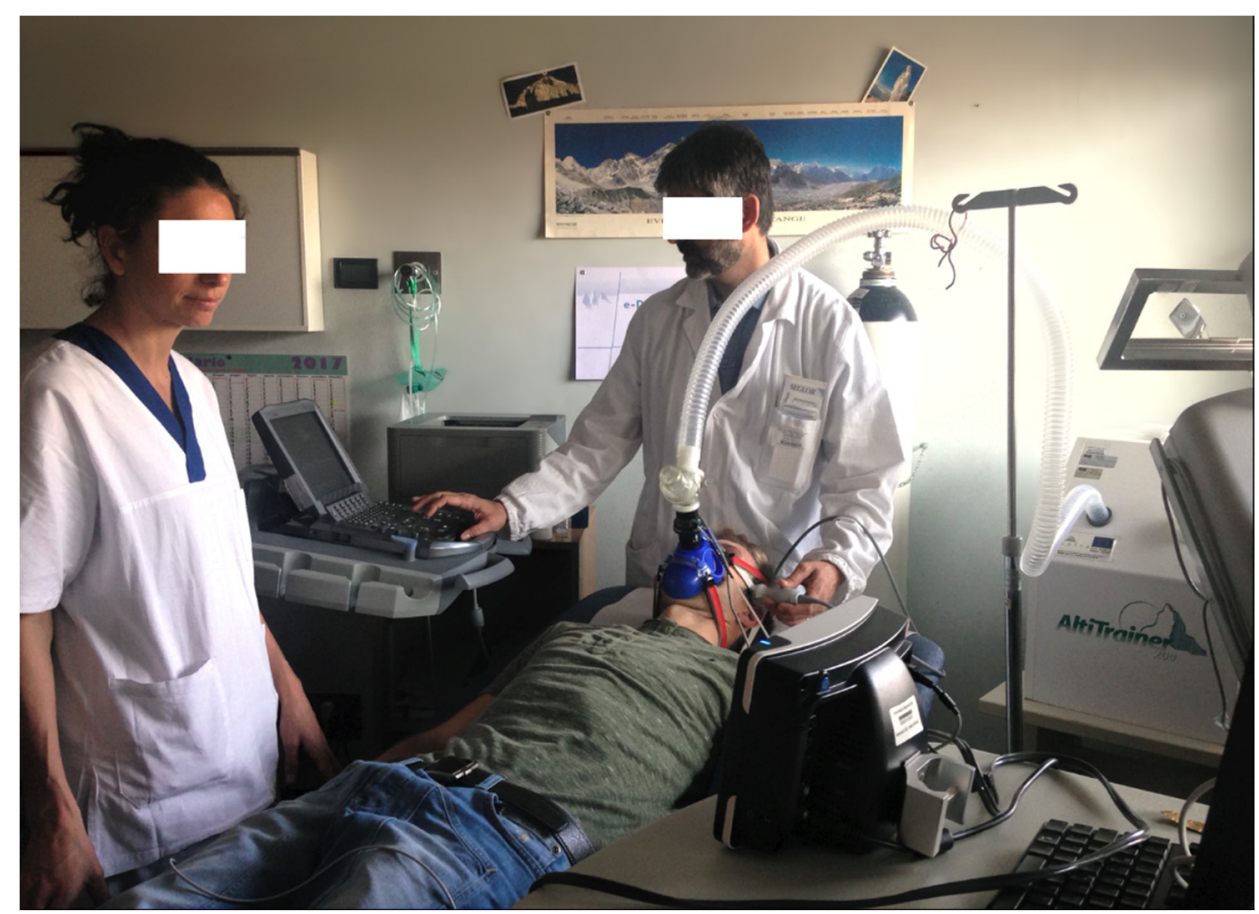

Figure 3. Cardiopulmonary rest test and cerebral blood flow (CBF) measurements in normobaric hypoxia $\left(\mathrm{FiO}_{2} 14 \%\right)$.

Acupressure was obtained by applying a "P6 nausea control sea band" (Sea-Band UK Ltd., Leicestershire, UK) bilaterally at least four hours before the test.

During the tests in hypoxia, all the subjects were given the Lake Louise questionnaire to record any symptoms.

\section{Statistical Analyses}

Using the descriptive statistic indices, interquartile range (IQR), mean, and standard deviation (sd) for continuous variables, and percentages for categorical variables, the normobaric hypoxia, acupuncture, and acupressure groups were described by the following characteristics: age, sex, height, BMI, previous symptoms of acute mountain sickness (AMS), and by physiological parameters $\left(\mathrm{SaO}_{2}, \mathrm{HR}\right.$, SBP, DBP, PSV, EDV, PI, RI).

Effects of hypoxia and acupuncture/acupressure between the same subjects at different times (baseline-hypoxia $5^{\prime}$-hypoxia; 15'-hypoxia) on CBF in MCA were evaluated using multilevel mixed-effects linear regression adjusted for age, AMS, and BMI. The analyses were performed using SPSS 23.0 (IBM Corp. Released 2020. IBM SPSS Statistics for Windows, Version 27.0. Armonk, NY, YSA: IBM Corp) and Stata/SE 13, College Station, TX, USA: StataCorp LP, considering a level of statistical significance at $p<0.05$.

\section{Results}

Despite the loss of follow-up in the B (acupressure) group, before and after the washout period, the characteristics of the subjects in the normobaric hypoxia, acupuncture, and acupressure groups were not different in terms of age (control-38 years; Acupuncture/Band38 years), BMI (control-21.46; Acupuncture/Band-21.93), and previous symptoms of acute mountain sickness (AMS $\geq 3$ ) (control-28.4\%; Acupuncture/Band-23.2\%).

Using the statistical descriptive indexes, after PC6 stimulation, the trend over time for each index showed an increase in $\mathrm{HR}$ values and a decrease in $\mathrm{SaO}_{2}$, and no variations in SBP and DBP (Table 1 and Figure 4). Additionally, PSV and EDV after hypoxia seemed to increase more in the control group, whereas for the other indices under examination, there were no differences in the measurements at the three time points (Table 2 and Figures 5-8). 
Table 1. Interquartile ranges (IQR), mean and standard deviation (sd) of oxyhaemoglobin saturation $\left(\mathrm{SaO}_{2}\right)$, heart rate $(\mathrm{HR})$, systolic and diastolic blood pressure (SBP and DBP) in controls, acupuncture and acupressure groups at baseline and after 5 and 15 min of hypoxia.

\begin{tabular}{|c|c|c|c|c|c|c|c|c|c|}
\hline \multirow[b]{2}{*}{ Groups } & \multirow[b]{2}{*}{ Time } & \multicolumn{2}{|c|}{$\begin{array}{c}\mathrm{SaO}_{2} \\
\text { (Percentage) }\end{array}$} & \multicolumn{2}{|c|}{$\begin{array}{c}\text { HR } \\
\text { (Beats per Minute) }\end{array}$} & \multicolumn{2}{|c|}{$\begin{array}{c}\text { SBP } \\
\text { (Millimeters of Mercury) }\end{array}$} & \multicolumn{2}{|c|}{$\begin{array}{c}\text { DBP } \\
\text { (Millimeters of Mercury) }\end{array}$} \\
\hline & & IQR & Mean (sd) & IQR & Mean (sd) & IQR & Mean (sd) & IQR & Mean (sd) \\
\hline \multirow{6}{*}{$\begin{array}{l}\text { control } \\
\left(\mathrm{n}^{\circ} 17\right)\end{array}$} & \multirow{2}{*}{ baseline } & 98 & 98.17 & 61 & 60.17 & 122 & 122.82 & 76 & 76.76 \\
\hline & & (98-98) & $(0.73)$ & $(55-65)$ & (7.79) & (113-131) & (12.59) & $(72-82)$ & $(8.01)$ \\
\hline & \multirow{2}{*}{ hypoxia $5^{\prime}$} & 92 & 92.17 & 64 & 65.24 & 119 & 122.0 & 75 & 76.71 \\
\hline & & $(91-93)$ & (1.97) & $(60-72)$ & (9.29) & (114-128) & (11.65) & $(71-81)$ & $(9.88)$ \\
\hline & \multirow{2}{*}{ hypoxia $15^{\prime}$} & 89 & 89.18 & 62 & 65.23 & 117 & 118.41 & 75 & 76.17 \\
\hline & & $(88-91)$ & $(2.69)$ & $(60-67)$ & (7.93) & $(111-124)$ & (11.36) & $(72-80)$ & $(8.17)$ \\
\hline \multirow{6}{*}{$\begin{array}{l}\text { acupuncture } \\
\left(\mathrm{n}^{\circ} 17\right)\end{array}$} & \multirow{2}{*}{ baseline } & 98 & 98.00 & 61 & 62.35 & 120 & 118.17 & 74 & 72.88 \\
\hline & & (97-99) & (1.17) & $(58-69)$ & (10.69) & (108-127) & (12.54) & $(69-75)$ & (9.03) \\
\hline & \multirow{2}{*}{ hypoxia $5^{\prime}$} & 91 & 91.06 & 67 & 66.58 & 116 & 116.53 & 72 & 71.47 \\
\hline & & $(90-93)$ & $(2.68)$ & $(61-72)$ & (11.09) & (109-125) & (13.99) & $(66-76)$ & $(9.22)$ \\
\hline & \multirow{2}{*}{ hypoxia $15^{\prime}$} & 90 & 88.94 & 67 & 67.58 & 112 & 115.76 & 71 & 71.82 \\
\hline & & $(86-91)$ & (3.98) & $(60-72)$ & (11.35) & $(109-123)$ & $(12.29)$ & $(67-77)$ & $(9.06)$ \\
\hline \multirow{6}{*}{$\begin{array}{l}\text { acupressure } \\
\left(n^{\circ} 9\right)\end{array}$} & \multirow{2}{*}{ baseline } & 98 & 98.33 & 60 & 60.77 & 113 & 114.44 & 70 & 71.44 \\
\hline & & (98-99) & $(0.49)$ & $(56-65)$ & (11.28) & (111-119) & $(6.87)$ & $(66-74)$ & $(8.52)$ \\
\hline & \multirow{2}{*}{ hypoxia $5^{\prime}$} & 90 & 90.00 & 66 & 64.33 & 111 & 112.77 & 73 & 73.66 \\
\hline & & (88-92) & $(3.00)$ & $(59-67)$ & (11.81) & $(110-116)$ & $(4.71)$ & $(68-78)$ & (5.19) \\
\hline & \multirow{2}{*}{ hypoxia $15^{\prime}$} & 87 & 86.55 & 65 & 64.00 & 112 & 112.55 & 70 & 71.77 \\
\hline & & $(84-88)$ & (3.61) & $(58-67)$ & (11.51) & $(112-117)$ & $(6.00)$ & $(68-77)$ & $(7.74)$ \\
\hline
\end{tabular}

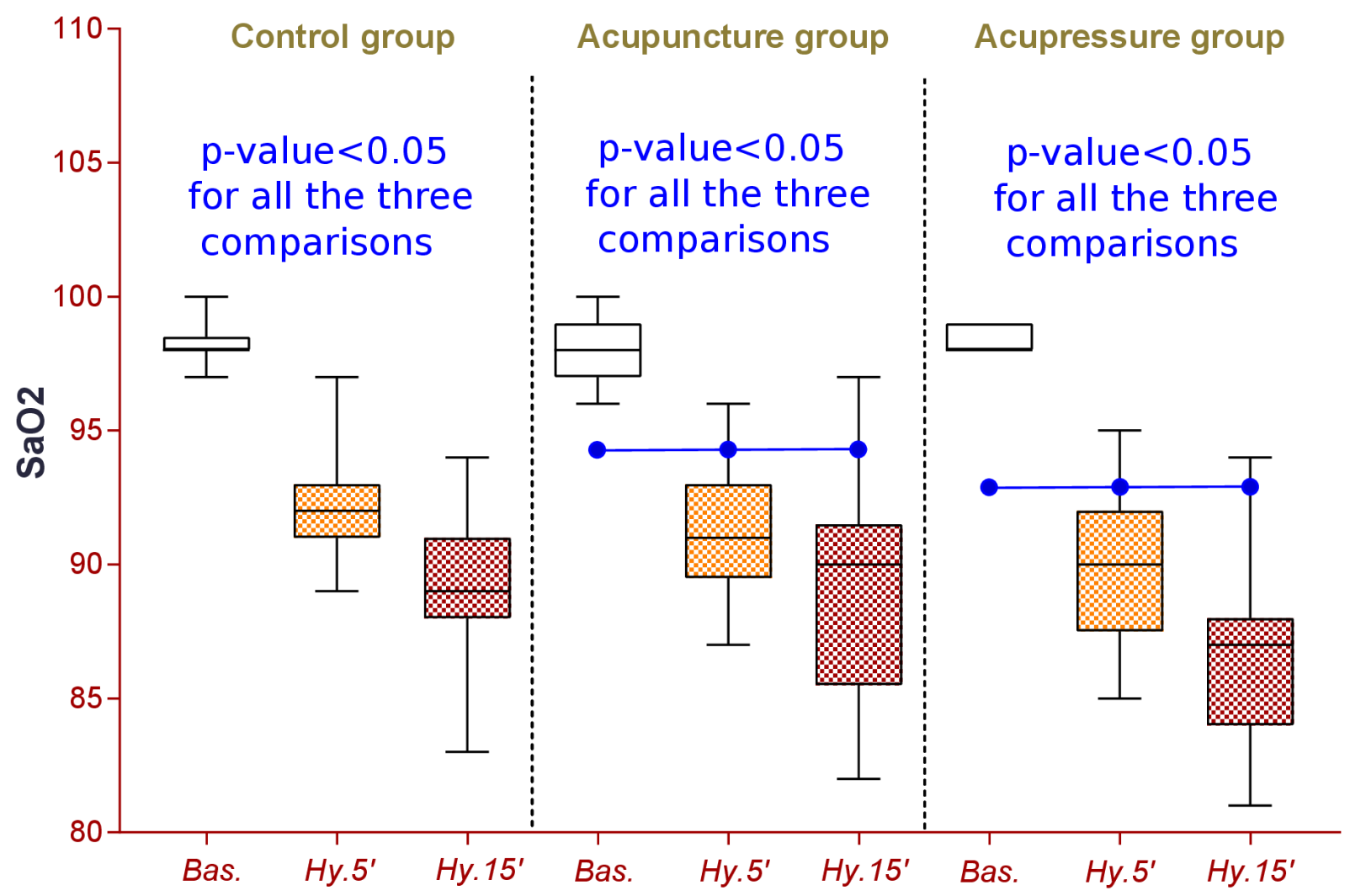

Figure 4. Descriptive analysis for percentage of oxyhaemoglobin saturation $\left(\mathrm{SaO}_{2}\right)$ in control, acupuncture, and band (acupressure) groups at baseline and after 5 and $15 \mathrm{~min}$ of hypoxia. 
Table 2. CBF parameters (PSV, EDV, PI, RI) in control, acupuncture and band (acupressure) groups at baseline, after 5 and 15 min of hypoxia.

\begin{tabular}{|c|c|c|c|c|c|c|c|c|c|}
\hline \multirow[b]{2}{*}{ Groups } & \multirow[b]{2}{*}{ Time } & \multicolumn{2}{|c|}{$\begin{array}{l}\text { PSV } \\
(\mathrm{cm} / \mathrm{s})\end{array}$} & \multicolumn{2}{|c|}{$\begin{array}{l}\text { EDV } \\
(\mathrm{cm} / \mathrm{s})\end{array}$} & \multicolumn{2}{|c|}{ PI ** } & \multicolumn{2}{|c|}{$\mathbf{R I}$ ** } \\
\hline & & IQR & Mean (sd) & IQR & Mean (sd) & IQR & Mean (sd) & IQR & Mean (sd) \\
\hline \multirow{6}{*}{$\begin{array}{l}\text { control } \\
\left(n^{\circ} 17\right)\end{array}$} & & 78.6 & 82.27 & 36.6 & 36.73 & 0.87 & 0.88 & 0.56 & 0.55 \\
\hline & baseline & (73.2-89.4) & (13.30) & $(31.2-38.8)$ & (7.37) & $(0.79-0.98)$ & $(0.11)$ & $(0.52-0.59)$ & $(0.04)$ \\
\hline & bouri $5^{\prime}$ & 82.9 & 84.16 & 38.8 & 38.37 & 0.86 & 0.84 & 0.54 & 0.54 \\
\hline & hypoxia $5^{\prime}$ & $(73.9-91)$ & (15.78) & $(32.4-43.1)$ & $(9.04)$ & $(0.72-0.93)$ & $(0.17)$ & $(0.48-0.59)$ & $(0.08)$ \\
\hline & Hypoxia $15^{\prime}$ & 91.5 & 93.28 & 44.1 & 43.78 & 0.81 & 0.81 & 0.53 & 0.53 \\
\hline & Hypoxia 15' & $(82.9-100.1)$ & (14.54) & $(36.8-45.9)$ & $(6.97)$ & $(0.75-0.87)$ & $(0.09)$ & $(0.51-0.56)$ & $(0.04)$ \\
\hline \multirow{6}{*}{$\begin{array}{l}\text { acupuncture } \\
\left(n^{\circ} 17\right)\end{array}$} & & 78.6 & 78.33 & 32.3 & 32.62 & 0.95 & 0.95 & 0.6 & 0.58 \\
\hline & baseline & (73.2-80.8) & (15.22) & $(31.2-36.6)$ & $(7.01)$ & $(0.84-1.03)$ & $(0.12)$ & $(0.56-0.62)$ & $(0.05)$ \\
\hline & & 83 & 84.65 & 36.6 & 37.73 & 0.83 & 0.87 & 0.55 & 0.55 \\
\hline & hypoxia $5^{\prime}$ & (75.4-91.6) & (13.27) & $(32.4-40.9)$ & $(6.55)$ & $(0.8-0.91)$ & $(0.14)$ & $(0.52-0.58)$ & $(0.05)$ \\
\hline & & 87.2 & 86.06 & 36.6 & 39.37 & 0.95 & 0.85 & 0.57 & 0.54 \\
\hline & hypoxia $15^{\prime}$ & $(81-93.7)$ & (15.65) & $(32.4-45.3)$ & $(9.25)$ & $(0.69-0.96)$ & $(0.20)$ & $(0.48-0.6)$ & $(0.09)$ \\
\hline \multirow{6}{*}{$\begin{array}{l}\text { acupressure } \\
\left(n^{\circ} 9\right)\end{array}$} & haseline & 77.5 & 77.75 & 32.3 & 34.67 & 0.88 & 0.87 & 0.56 & 0.55 \\
\hline & baseline & (73.2-78.6) & (12.06) & $(31.2-32.3)$ & (7.37) & $(0.78-0.97)$ & $(0.12)$ & $(0.52-0.6)$ & (0.05) \\
\hline & hypoxia $5^{\prime}$ & 76 & 80.75 & 36.6 & 38.05 & 0.8 & 0.79 & 0.55 & 0.52 \\
\hline & & (73.2-93.7) & $(16.81)$ & (32.3-43.2) & (6.09) & $(0.68-0.86)$ & $(0.12)$ & $(0.47-0.56)$ & $(0.05)$ \\
\hline & hypoxia $15^{\prime}$ & 87.4 & 87.64 & 40.9 & 42.64 & 0.83 & 0.77 & 0.53 & 0.51 \\
\hline & & (77.5-93.7) & $(16.61)$ & (38.9-45.3) & (6.19) & $(0.66-0.85)$ & $(0.11)$ & $(0.47-0.55)$ & $(0.05)$ \\
\hline
\end{tabular}

** PI is used as a measure of impedance of the flow of blood distal to the sampling point and is automatically calculated according to the formula PI $=(s-d) /$ mean, where $s$ is the peak, $d$ is the minimum, and the average is the mean maximum Doppler shift frequency over the cardiac cycle. $\mathrm{RI}$ is automatically calculated using the formula $\mathrm{RI}=[(\mathrm{s}-\mathrm{d}) / \mathrm{s}] \times \mathrm{s}-$ peak systolic; $\mathrm{d}$ —end-diastolic.

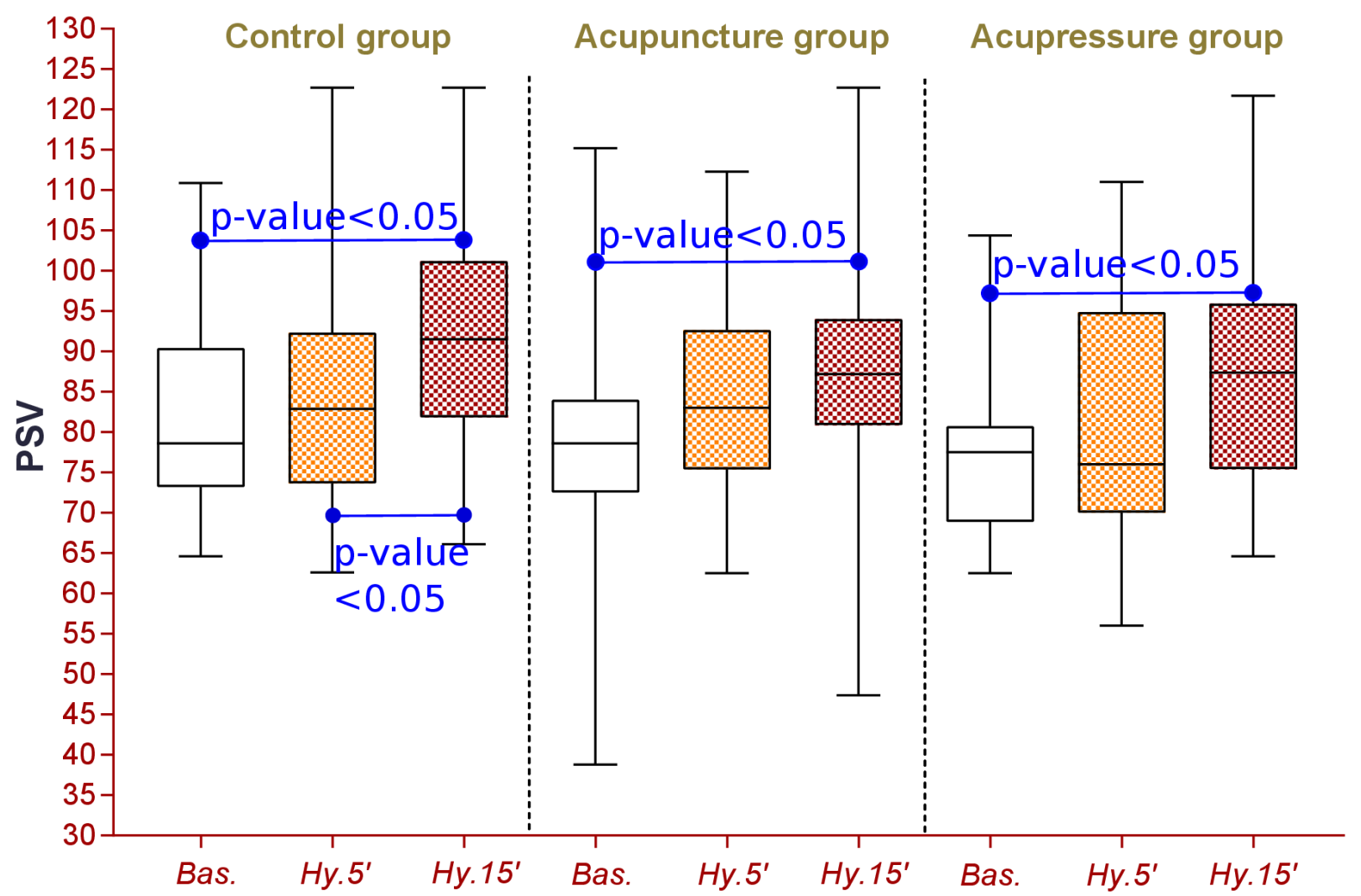

Figure 5. Centimeters per second peak systolic velocity (PSV) in control, acupuncture, and band (acupressure) groups at baseline and after 5 and 15 min of hypoxia. 


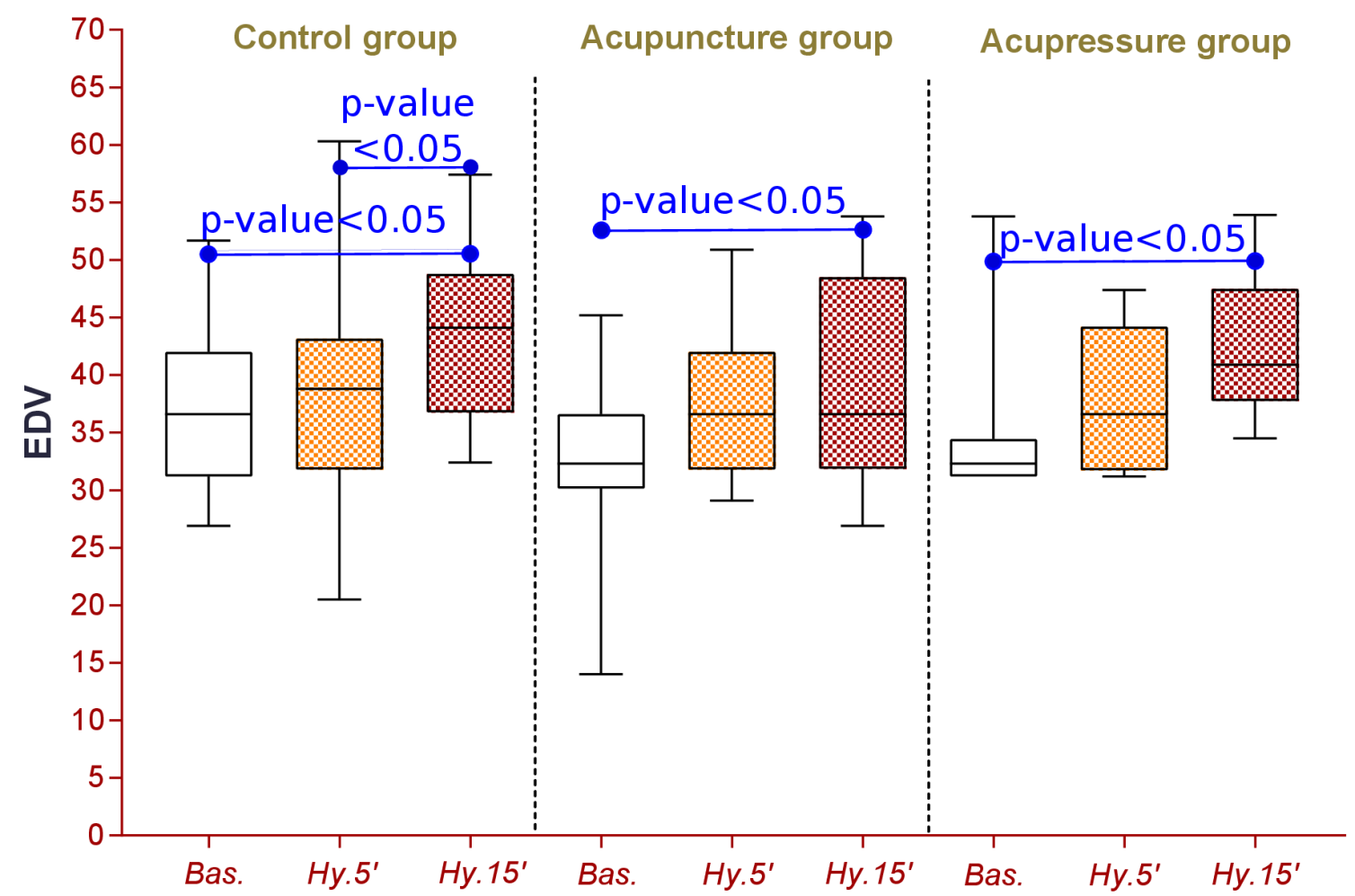

Figure 6. Centimeters per second end diastolic velocity (EDV) in control, acupuncture, and band (acupressure) groups at baseline and after 5 and 15 min of hypoxia.

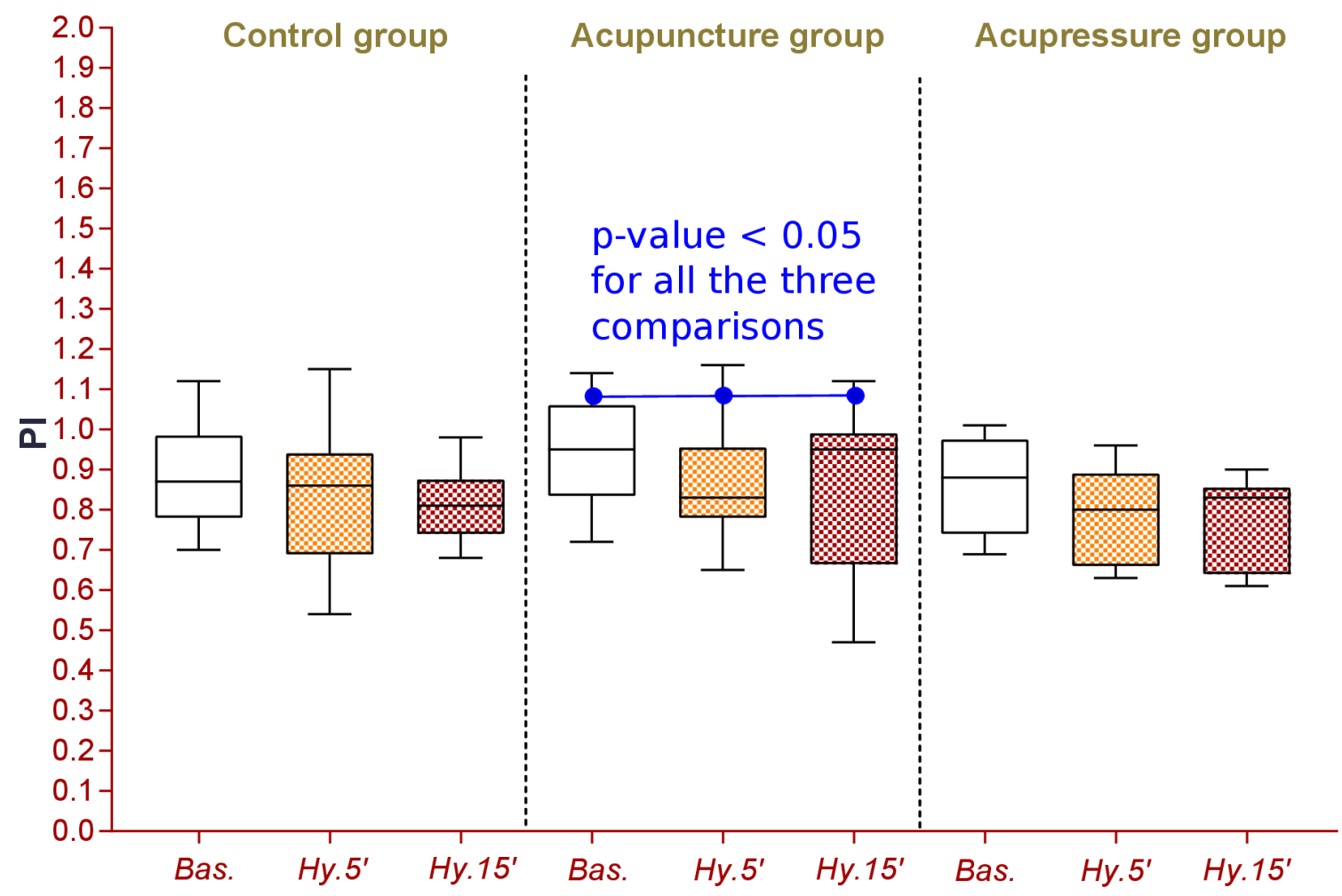

Figure 7. Calculated as in Table 2. Pulsatility Index (PI) in control, acupuncture, and band (acupressure) groups at baseline and after 5 and 15 min of hypoxia. 


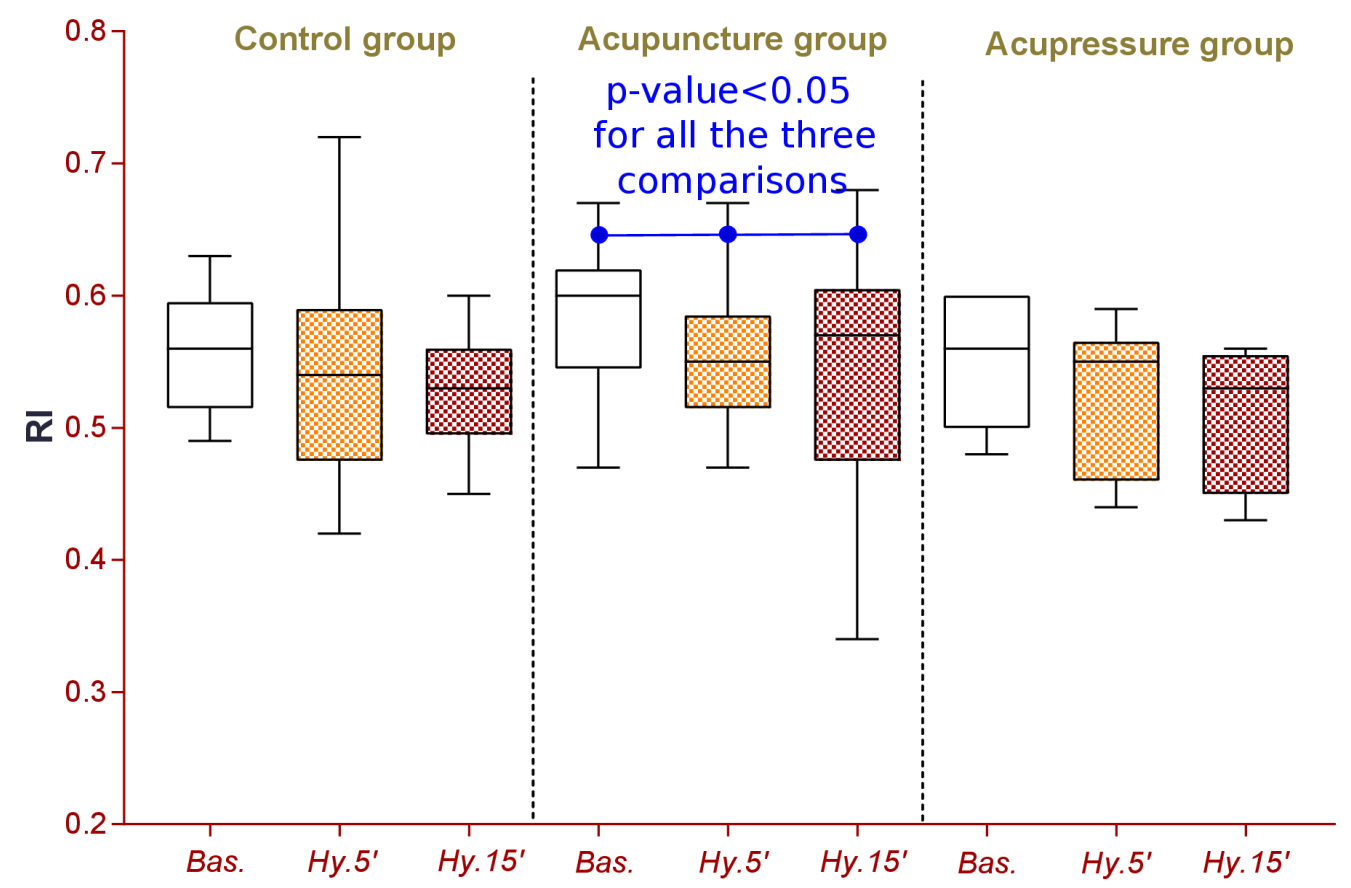

Figure 8. Calculated as in Table 2. Resistive Index (RI) in control, acupuncture, and band (acupressure) groups at baseline and after 5 and $15 \mathrm{~min}$ of hypoxia.

\subsection{Control Group}

Breathing a hypoxic mixture $\left(\mathrm{FiO}_{2}=14 \%\right)$, without acupuncture or acupressure, induced in all the subjects examined a clear and highly significant reduction in $\mathrm{SaO}_{2}$, from 98.17 ( \pm 0.73$)$ to 92.17 ( \pm 1.97$)$ after $5 \mathrm{~min}$ of hypoxia, and with a further reduction to $89.18( \pm 2.69)$ after $15 \mathrm{~min}$ of hypoxia.

HR also increased significantly from $60.17 \mathrm{bpm}( \pm 7.79)$ to $65.24 \mathrm{bpm}( \pm 9.29)$ after 5 min of hypoxia, remaining stable over the next ten minutes at $65.23 \mathrm{bpm}( \pm 7.93)$.

SBP decreased slightly, but significantly, after $15 \mathrm{~min}$ of hypoxia, from $122.82 \mathrm{mmHg}$ $( \pm 12.59)$ to $118.41 \mathrm{mmHg}( \pm 11.36)$, while DBP did not change (baseline 76.75 ; hypoxia $5^{\prime} 75$; hypoxia $15^{\prime} 75$; control group parameters value are shown in Table 1 while significance between the three measurements is shown in Figures 4 and 9-11).

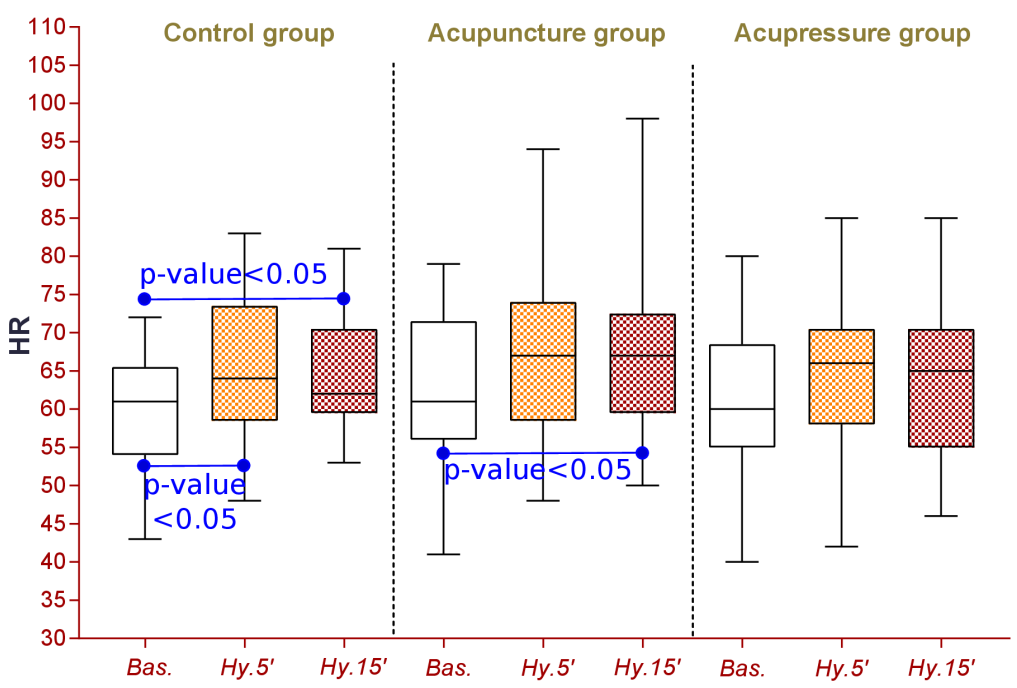

Figure 9. Descriptive analysis for heart rate (HR) beats for minute in control, acupuncture, and band (acupressure) groups at baseline and after 5 and $15 \mathrm{~min}$ of hypoxia. 


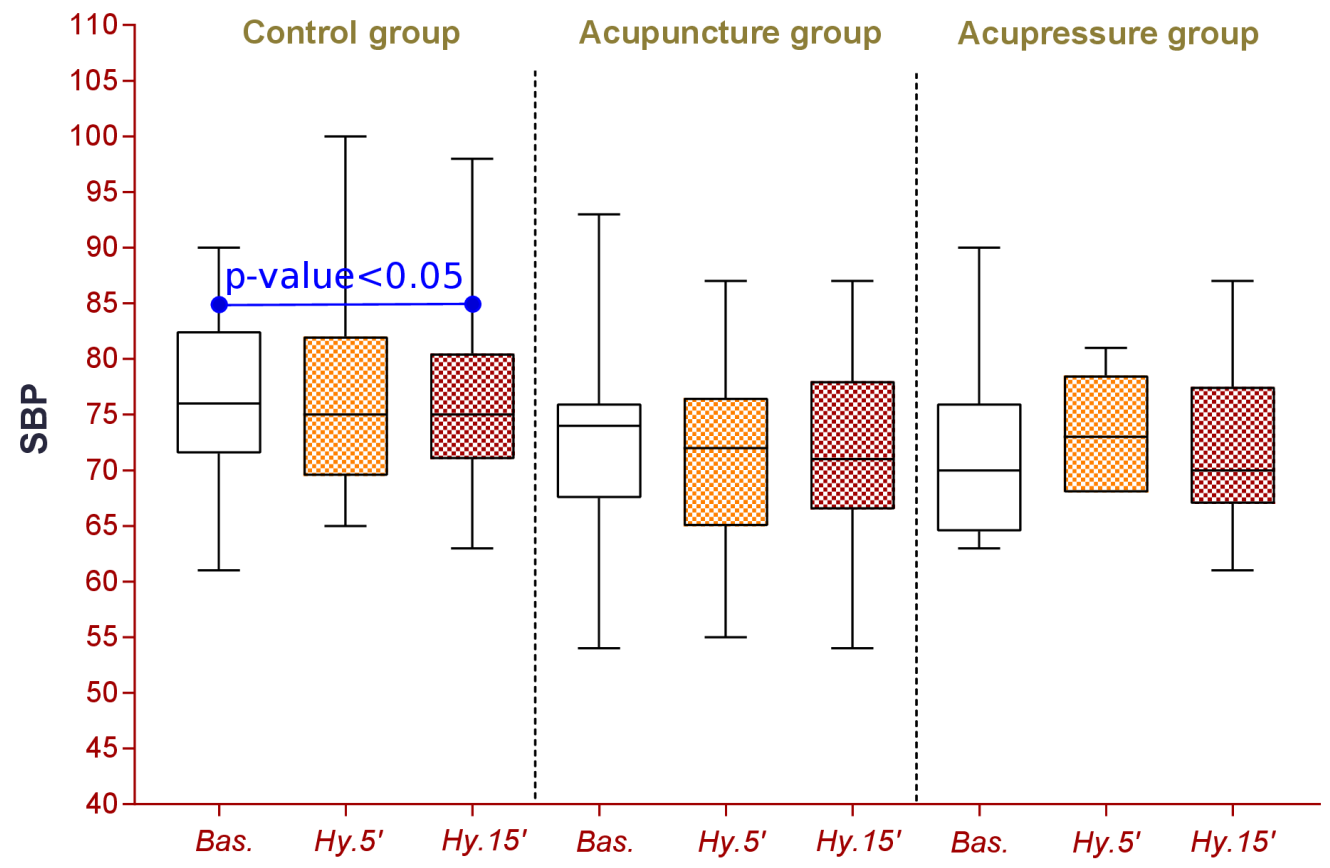

Figure 10. Descriptive analysis for millimeters of mercury systolic blood pressure (SBP) in control, acupuncture, and band (acupressure) groups at baseline and after 5 and 15 min of hypoxia.

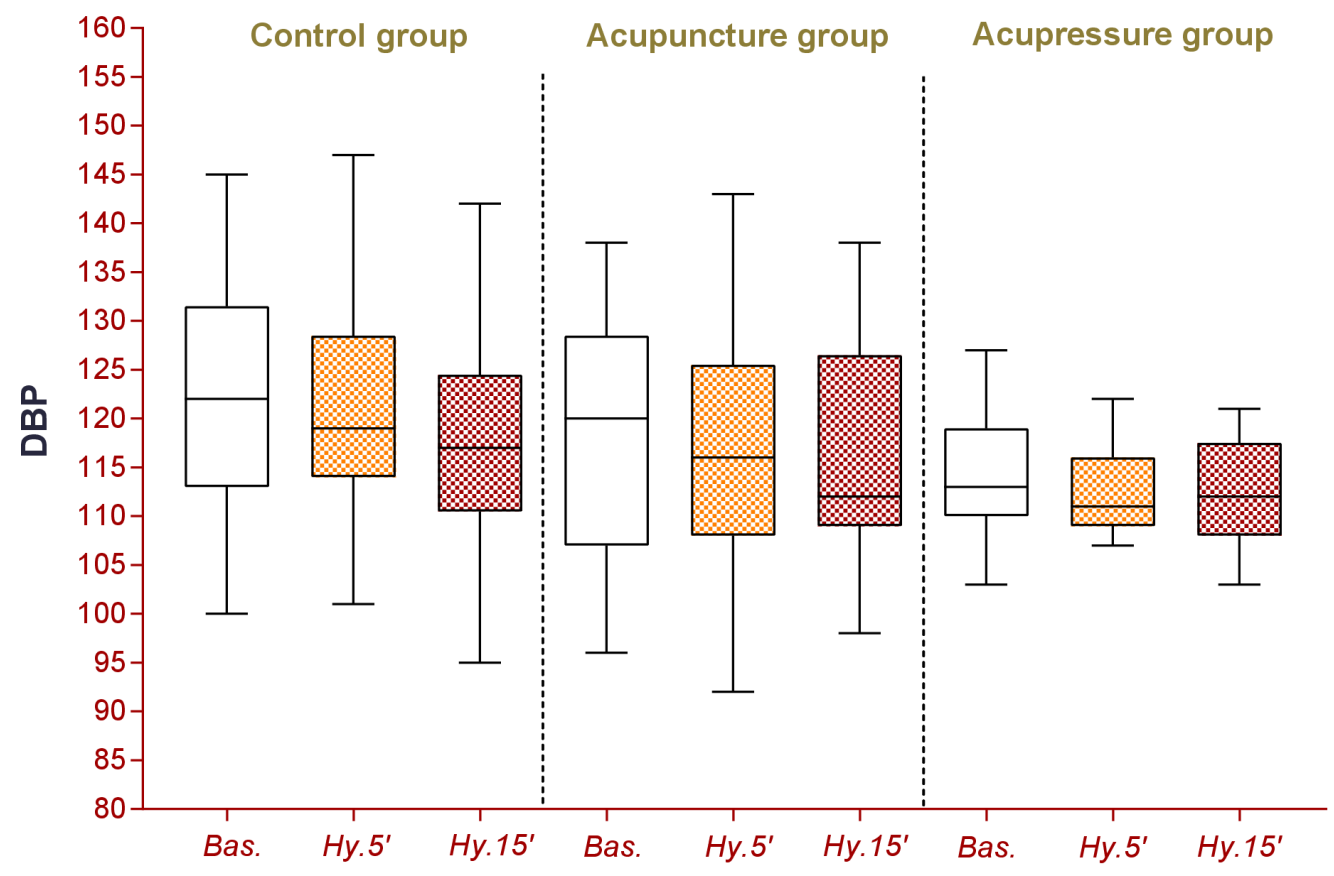

Figure 11. Descriptive analysis for millimeters of mercury of diastolic blood pressure (DBP) in control, acupuncture, and band (acupressure) groups at baseline and after 5 and $15 \mathrm{~min}$ of hypoxia.

Both the PSV and the EDV, measured at the MCA, increased significantly, from $82.27 \mathrm{~cm} / \mathrm{s}( \pm 13.30)$ to $93.28 \mathrm{~cm} / \mathrm{s}( \pm 14.54)$, and from $36.73 \mathrm{~cm} / \mathrm{s}( \pm 7.37)$ to $43.78 \mathrm{~cm} / \mathrm{s}$ ( \pm 6.97 ) respectively, after 15 min of hypoxia (Table 2 Control group and Figure $4 \mathrm{~b}$ ).

PI and RI both decreased, from $0.88( \pm 0.11)$ to $0.81( \pm 0.09)$, and from $0.55( \pm 0.04)$ to $0.53( \pm 0.04)$, respectively, after $15 \mathrm{~min}$ of hypoxia. 


\subsection{Acupuncture Group}

Additionally, in the acupuncture group, there was a reduction in $\mathrm{SaO}_{2}(98.0( \pm 1.17)$ to 91.06 ( \pm 2.68 ) after $5 \mathrm{~min}$ of hypoxia, to 88.94 ( \pm 3.98 ) after $15 \mathrm{~min}$ of hypoxia), and in HR (62.35 ( \pm 10.69$)$ to $66.58( \pm 11.09)$ after $5 \mathrm{~min}$ of hypoxia, to $67.58( \pm 11.35)$ after $15 \mathrm{~min}$ of hypoxia).

SBP and DBP both decreased, from $118.17( \pm 12.54)$ to $115.76( \pm 12.29)$, and from 72.88 ( \pm 9.03$)$ to $71.82( \pm 9.06)$, respectively, after 15 min of hypoxia.

Both the PSV and the EDV, measured at the MCA, increased from $78.33 \mathrm{~cm} / \mathrm{s}( \pm 15.22)$ to $86.06 \mathrm{~cm} / \mathrm{s}( \pm 15.65)$, and from $32.62 \mathrm{~cm} / \mathrm{s}( \pm 7.01)$ to $39.37 \mathrm{~cm} / \mathrm{s}( \pm 9.25)$, respectively, after $15 \mathrm{~min}$ of hypoxia (acupuncture group parameter values are shown in Table 2 while significance over three measurements is shown in Figure 4, Figures 9-11).

PI and RI both decreased, from $0.95( \pm 0.12)$ to $0.85( \pm 0.20)$, and from $0.58( \pm 0.05)$ to $0.54( \pm 0.09)$, respectively, after $15 \mathrm{~min}$ of hypoxia.

\subsection{Acupressure Group}

In the acupressure group, there was a reduction in the following parameters after 15 min of hypoxia: $\mathrm{SaO}_{2}$ (from $98.33( \pm 0.49)$ to $86.55( \pm 3.61)$ ), SBP (from $114.44( \pm 6.87)$ to $112.55( \pm 6$.$) ), DBP (from 71.44( \pm 8.52)$ to $71.77( \pm 7.74)$ ), PI (from $0.87( \pm 0.12)$ to $0.77( \pm 0.11)$ ), and RI (from $0.55( \pm 0.05)$ to $0.51( \pm 0.05)$ ). $\mathrm{SaO}_{2}$ decreased from $98.33( \pm 0.49)$ to $86.55( \pm 3.61)$ after $15 \mathrm{~min}$ of hypoxia. Finally, PSV and EDV increased from $77.75 \mathrm{~cm} / \mathrm{s}$ $( \pm 2.06)$ to $87.64 \mathrm{~cm} / \mathrm{s}( \pm 16.61)$, and from $34.67 \mathrm{~cm} / \mathrm{s}( \pm 7.37)$ to $42.64 \mathrm{~cm} / \mathrm{s}( \pm 6.97)$, respectively, after $15 \mathrm{~min}$ of hypoxia (acupressure group parameters value are shown in Table 2 while significance over the three measurements is shown in Figure 4, Figures 9-11).

\subsection{Multilevel Mixed-Effects Linear Regression}

Through multilevel mixed-effects linear regression, we evaluated CBF in MCA in normoxia, and after 5 and $15 \mathrm{~min}$ in normobaric hypoxia $\left(\mathrm{FiO}_{2} 14 \%\right.$ corresponding to $3600 \mathrm{~m}$ a.s.l.), in the control group and after PC6 stimulation.

Compared to normoxia, $5 \mathrm{~min}$ in normobaric hypoxia caused a decrease in $\mathrm{SaO}_{2}$ of approximately 7 units (Beta $-6.86: 95 \% \mathrm{CI}-7.71 /-6.01, p$-value $=0.000$ ), and the decrease was greater after $15 \mathrm{~min}$ (about 10 units of $\mathrm{SaO}_{2}$; Beta $-9.60: 95 \% \mathrm{CI}-10.46 /-8.75, p$-value 0.001 ). We observed a reduction effect of PC6 acupressure (acupressure, Beta $-1.6295 \%$ CI $-3.00 /-0.24$, $p$-value 0.021), and none for acupuncture (Beta -0.51 : $95 \% \mathrm{CI}-1.65 / 0.63, p$-value 0.380 ). Having a previous episode of AMS and BMI did not seem to have any effect on the $\mathrm{SaO}_{2}$ variation (Table 3).

Table 3. Evaluation of oxyhaemoglobin saturation $\left(\mathrm{SaO}_{2}\right)$, heart rate $(\mathrm{HR})$, systolic and diastolic blood pressure (SBP and DBP) in normoxia, in acute normobaric hypoxia for $15 \mathrm{~min}$, in basal conditions, and after PC6 stimulation. Multilevel mixedeffects linear regression adjusted for age, acute mountain sickness (AMS), and body mass index (BMI) multivariate analysis.

\begin{tabular}{|c|c|c|c|c|c|c|c|}
\hline & \multirow{2}{*}{$\begin{array}{c}\begin{array}{c}\mathrm{SaO}_{2} \\
\text { (Percentage) }\end{array} \\
\text { Beta } \\
(95 \% \mathrm{CI})\end{array}$} & \multicolumn{2}{|c|}{$\begin{array}{c}\text { HR } \\
\text { (Beats per Minute) }\end{array}$} & \multicolumn{2}{|c|}{$\begin{array}{c}\text { BSP } \\
\text { (Millimeters of Mercury) }\end{array}$} & \multicolumn{2}{|c|}{$\begin{array}{c}\text { BDP } \\
\text { (Millimeters of Mercury) }\end{array}$} \\
\hline & & $p$ & Beta $(95 \% \mathrm{CI})$ & $p$ & Beta $(95 \% \mathrm{CI})$ & $p$ & Beta $(95 \%$ CI) \\
\hline age & $\begin{array}{c}0.09 \\
(0.01 / 0.17)\end{array}$ & $0.020 *$ & $\begin{array}{c}-0.25 \\
(-0.65 / 0.15)\end{array}$ & 0.223 & $\begin{array}{c}-0.05 \\
(-0.41 / 0.32)\end{array}$ & 0.800 & $\begin{array}{c}0.16 \\
(-0.14 / 0.47)\end{array}$ \\
\hline AMS $(\geq 3)$ & $\begin{array}{c}-0.63 \\
(-1.88 / 0.61)\end{array}$ & 0.320 & $6.79(0.53 / 13.05)$ & $0.034 *$ & $\begin{array}{c}6.28 \\
(0.61 / 11.95)\end{array}$ & 0.030 * & $\begin{array}{c}1.5 \\
(-3.28 / 6.29)\end{array}$ \\
\hline BMI & $\begin{array}{c}-0.04 \\
(-0.23 / 0.14)\end{array}$ & 0.632 & $1.06(0.15 / 1.98)$ & $0.022 *$ & $\begin{array}{c}2.47 \\
(1.64 / 3.29)\end{array}$ & $0.000 *$ & $1.21(0.51 / 1.91)$ \\
\hline normobaric hypoxia & reference & & reference & & reference & & Reference \\
\hline hypoxia $5^{\prime}$ & $\begin{array}{c}-6.86 \\
(-7.71 /-6.01)\end{array}$ & $0.000 *$ & $4.42(2.76 / 6.08)$ & $0.000 *$ & $\begin{array}{c}-1.33 \\
(-3.04 / 0.38)\end{array}$ & 0.129 & $\begin{array}{c}-0.12 \\
(-1.69 / 1.45)\end{array}$ \\
\hline hypoxia $15^{\prime}$ & $\begin{array}{c}-9.60 \\
(-10.46 /-8.75)\end{array}$ & $0.000 *$ & $4.74(3.08 / 6.41)$ & $0.000 *$ & $\begin{array}{c}-3.09 \\
(-4.80 /-1.38)\end{array}$ & 0.000 * & $\begin{array}{c}-0.58 \\
(-2.15 / 0.99)\end{array}$ \\
\hline controls & reference & & reference & & reference & & Reference \\
\hline acupuncture & $\begin{array}{c}-0.51 \\
(-1.65 / 0.63)\end{array}$ & 0.380 & $\begin{array}{c}1.96 \\
(-3.74 / 7.66)\end{array}$ & 0.500 & $\begin{array}{c}-4.25 \\
(-9.42 / 0.91)\end{array}$ & 0.107 & $\begin{array}{c}-4.49 \\
(-8.85 /-0.13)\end{array}$ \\
\hline acupressure & $\begin{array}{c}-1.62 \\
(-3.00 /-0.24)\end{array}$ & $0.021 *$ & $\begin{array}{c}0.68 \\
(-6.23 / 7.59)\end{array}$ & 0.848 & $\begin{array}{c}-5.72 \\
(-12.0 / 0.54)\end{array}$ & 0.063 & $\begin{array}{c}-3.33 \\
(-8.62 / 1.95)\end{array}$ \\
\hline
\end{tabular}


With regards to the PSV, the transition from normoxia to $5 \mathrm{~min}$ in normobaric hypoxia caused an increase of approximately 4 units (Beta 3.87: 95\% CI 0.38/7.36, p-value 0.030) and, as expected, the increase is greater after 15 min (about 9 units of VSP; Beta 9.48: 95\% CI 5.99/12.97, $p$-value 0.001). On the contrary, no effects of PC6 stimulation were observed (acupuncture, Beta -3.55: 95\% CI 10.44/3.33, p-value 0.312; acupressure, Beta -4.34: $95 \%$ CI -12.68/4.00, $p$-value 0.308). The AMS score for previous exposure to high altitudes was directly correlated to an increase in PSV of approximately 13 units (Beta 3.87: 95\% CI 0.38/7.36, p-value 0.001).

Similar results were observed for EDV. However, after 5 and 15 min of hypoxia, the effects of hypoxia on HR, PI, and RI were the same, and no effect of PC6 stimulation was confirmed (Table 4).

Table 4. Evaluation of blood flow oxyhaemoglobin saturation $\left(\mathrm{SaO}_{2}\right)$, heart rate (HR), Resistive Index (RI), and Pulsatility Index (PI) in the middle cerebral artery (MCA) in normoxia, in acute normobaric hypoxia for 15 min, in basal conditions, and after PC6 stimulation. Multilevel mixed-effects linear regression adjusted for age, acute mountain sickness (AMS), and body mass index (BMI) multivariate analysis.

\begin{tabular}{|c|c|c|c|c|c|c|c|}
\hline & \multirow{2}{*}{$\begin{array}{c}\begin{array}{c}\text { PSV } \\
(\mathrm{cm} / \mathrm{s})\end{array} \\
\begin{array}{c}\text { Beta } \\
(95 \% \mathrm{CI})\end{array}\end{array}$} & \multicolumn{2}{|c|}{$\begin{array}{l}\mathrm{EDV} \\
(\mathrm{cm} / \mathrm{s})\end{array}$} & \multicolumn{2}{|c|}{ PI ** } & \multicolumn{2}{|c|}{$\mathbf{R I}^{* *}$} \\
\hline & & $p$ & $\begin{array}{c}\text { Beta } \\
(95 \% \text { CI })\end{array}$ & $p$ & $\begin{array}{c}\text { Beta } \\
(95 \% \text { CI })\end{array}$ & $p$ & $\begin{array}{c}\text { Beta } \\
(95 \% \mathrm{CI})\end{array}$ \\
\hline Age & $\begin{array}{c}0.16 \\
(-0.33 / 0.64)\end{array}$ & 0.525 & $\begin{array}{c}0.03 \\
(-0.22 / 0.28)\end{array}$ & 0.825 & $\begin{array}{c}0.00 \\
(-0.01 / 0.01)\end{array}$ & 0.764 & $0.00(0.00 / 0.00)$ \\
\hline AMS $(\geq 3)$ & $\begin{array}{c}12.67 \\
(5.12 / 20.23)\end{array}$ & $0.001 *$ & $\begin{array}{c}3.58 \\
(-0.31 / 7.46)\end{array}$ & 0.071 & $\begin{array}{c}0.06 \\
(-0.01 / 0.12)\end{array}$ & 0.116 & $\begin{array}{c}0.03 \\
(-0.01 / 0.06)\end{array}$ \\
\hline BMI & $\begin{array}{c}-1.10 \\
(-2.21 /-0.01)\end{array}$ & $0.049 *$ & $\begin{array}{c}-0.71 \\
(-1.27 /-0.14)\end{array}$ & $0.015^{*}$ & $0.01(0.00 / 0.02)$ & $0.024 *$ & $0.00(0.00 / 0.01)$ \\
\hline normobaric hypoxia & reference & & reference & & reference & & Reference \\
\hline hypoxia $5^{\prime}$ & $3.87(0.38 / 7.36)$ & 0.030 * & $3.37(1.32 / 5.43)$ & $0.001 *$ & $\begin{array}{c}-0.07 \\
(-0.11 /-0.02)\end{array}$ & $0.005^{*}$ & $\begin{array}{c}-0.02 \\
(-0.04 /-0.00)\end{array}$ \\
\hline hypoxia $15^{\prime}$ & $9.48(5.99 / 12.97)$ & $0.000 *$ & $7.12(5.07 / 9.17)$ & $0.000 *$ & $\begin{array}{c}-0.09 \\
(-0.14 /-0.04) \\
\end{array}$ & $0.000 *$ & $\begin{array}{c}-0.04 \\
(-0.06 /-0.02)\end{array}$ \\
\hline controls & reference & & reference & & reference & & Reference \\
\hline acupuncture & $\begin{array}{c}-3.55 \\
(-10.44 / 3.33)\end{array}$ & 0.312 & $\begin{array}{c}-3.05 \\
(-6.60 / 0.49)\end{array}$ & 0.081 * & $\begin{array}{c}0.05 \\
(-0.02 / 0.11)\end{array}$ & 0.154 & $\begin{array}{c}0.02 \\
(-0.01 / 0.05)\end{array}$ \\
\hline acupressure & $\begin{array}{c}-4.34 \\
(-12.68 / 4.00)\end{array}$ & 0.308 & $\begin{array}{c}-1.38 \\
(-5.68 / 2.91)\end{array}$ & 0.527 & $\begin{array}{c}-0.02 \\
(-0.10 / 0.05)\end{array}$ & 0.563 & $\begin{array}{c}-0.01 \\
(-0.05 / 0.03)\end{array}$ \\
\hline
\end{tabular}

* $p$-value $<0.05 ;{ }^{* *}$ Calculated as in Table 2.

Considering PC6 stimulation as a whole (acupuncture and acupressure as a single group vs control group), SBP (Beta -4.09 : 95\% CI -8.07/ - 0.11, p-value 0.034) and DBP (Beta -4.75 : 95\% CI $-9.47 /-0.03$, $p$-value 0.038 ) significantly decreased after hypoxia, compared to the control group. Furthermore, the decrease in $\mathrm{SaO}_{2}$ was no longer significant (Beta -2.38: 95\% CI -7.89/3.13, p-value 0.397).

No symptoms of AMS were observed during hypoxia, nor during PC6 stimulation.

\section{Discussion}

In all the subjects recruited, acute normobaric hypoxia caused a significant increase in PSV and EDV, and a reduction in PI and RI-in agreement with the data of Bian.

The results of PC6 stimulation (both by needle and wristband) evidenced a tendency to contrast the actions of acute normobaric hypoxia. PSV and EDV did indeed increase significantly in hypoxia, but during PC6 stimulation, the increase was minor-at least with regard to EDV-even if variations were not statistically significant. Additionally, the reduction of PI and RI after 15 min of normobaric hypoxia was not significant during PC6 stimulation, both by needle and wristband. Even if Quirico and Allais described a significant reduction of average BFV in MCA, during PC6 pricking, in women with and without migraine, from our data we cannot see any significant effect of PC6 stimulation. A possible explanation could be the limited number of the subjects we were able to recruit and the high standard deviation of the results. 
The reduction in oxyhaemoglobin saturation during hypoxia was similar without and with PC6 stimulation. PC6 does not seem to have any effect on ventilation, according to the absence of action on respiratory Qì, as reported in TCM. Systemic arterial pressure-both systolic and diastolic - after the short period of hypoxia at rest, showed a slight, significant decrease after PC6 stimulation, when acupuncture and acupressure were considered together. From our data it therefore seems that in the first fifteen minutes of hypoxia, the action of PC6 stimulation could be both on the CBF, and, according to TCM, on cardiovascular function.

The hypothesized effect of PC6 stimulation against the increase of CBF velocity induced by acute hypoxia cannot be excluded. Looking at the correlation between the AMS score of previous exposure to high altitudes and the increase of PSV values during hypoxia, there could be a "re-balance" of the CBF. This action could favour better cerebral oxygenation and counteract the onset of symptoms of AMS, such as headache, nausea, and insomnia. On the other hand, the PC6 point acts on the brain and counteracts what in TCM is called "the rebellious Qi of stomach", and in Western medicine is represented by nausea and vomiting. A lower systemic arterial pressure could also be less damaging to capillary endothelial cells, but further studies are needed to support all these hypotheses.

We made the choice not to use a "placebo" group-with the "placebo" treatment being sham acupuncture-because in the literature this has been shown to be unreliable. Sham acupuncture methods should be not only credible (for the patients) and blinded, but also inert. To our knowledge, no physiological studies on the possible effects of sham acupuncture have been performed up to now. Some studies have indicated that sham acupuncture can also produce a therapeutic response and elicit neurobiological responses at various levels in the central nervous system [32]. In some trials, sham acupuncture was as effective as real acupuncture [33], or even more effective [34]. According to Birch [35], none of the different types of sham acupuncture can be accepted as a placebo control because they are not indistinguishable and are not physiologically inert.

This study has some limitations. The first is the shortness of the hypoxic stimulus. We are conscious that a short stimulus cannot have triggered AMS during our test; in fact, AMS symptoms appear between six and thirty-six hours of exposure to hypoxia. Therefore, we cannot say anything about the possibility of using acupoint PC6 in the treatment and prevention of these symptoms. Moreover, the test was conceived on the basis of other predictive tests, both at rest and under exertion, with the specific aim of investigating highaltitude illness susceptibility in simulated altitudes [36,37]. The effects of PC6 stimulation on cerebral circulation in hypoxic conditions should be investigated in a field study after exposure to acute hypobaric hypoxia for at least $24 \mathrm{~h}$, as in Bian's study. From Bian's data, it also appears that acute hypobaric hypoxia mainly affects the posterior cerebral circulation, which was not investigated in this study.

A second limitation of this study is the technique of measuring the MCA flow. Variations in cerebral blood flow depend not only on the flow velocity, but also on the diameter of the vessels. Their measurement would be desirable, even using trans-cranial echo-color Doppler, which, according to Wilson [38], closely correlates with the values obtained with magnetic resonance. Such a measurement would be possible in a different study design providing more time for the measurements-not limited to one minute.

\section{Conclusions}

From our data, PC6 stimulation seems to contrast the increase in CBF velocity, especially EDV, induced by acute normobaric hypoxia.

A rearranged balance of CBF in hypoxia, as induced by PC6 stimulation, could help to prevent or treat AMS symptoms. Among the TCM clinical indications of PC6, there are chest pain and oppression, gastric pain, nausea and vomiting, and insomnia. All of these are symptoms of AMS. Moreover, a blunted PSV in hypoxia could be less injurious to capillary endothelial cells, but further studies are necessary to support these hypotheses. 
The next step of our project is planned to be the evaluation of the CBF and the AMS score at high altitudes, immediately after a rapid ascent by cable car and after an overnight stay, using PC6 stimulation only through pressure, obtained with the elastic wristband. We are designing a randomized double-blind study using a "placebo" wristband, without the pressure button on the skin side. Unfortunately, the Covid-19 pandemic has stopped our projects for two years.

Given that few published investigations have explored the effects of PC6 stimulation in a simulated altitude, which is often regarded as an incomplete surrogate of "true" altitude, studies at terrestrial altitudes are necessary. This pilot study encourages future investigations on altitude to further probe the potentially beneficial effects of PC6 stimulation under highly defined conditions to compare the trend of the indicators at high altitudes in relation to acute mountain sickness and other pathologies caused by hypoxia.

Author Contributions: O.P., M.M., G.L., G.G. and L.B. conceived of the presented idea, developed the theory and performed the computations. O.P., S.B., L.C., M.S. and G.G. carried out the experiment. O.P., M.M., G.L., G.G., O.S., D.M. and L.B. verified the analytical methods. All authors discussed the results and contributed to the final manuscript. All authors have read and agreed to the published version of the manuscript.

Funding: This research received no external funding. P6 SEA-BAND were kindly and freely supplied by Consulteam s.a.s. (Misano Adriatico), the importer and distributor of P6 SEA-BANDs on behalf of SEA-BAND Ltd. UK.

Institutional Review Board Statement: This study was conducted according to the guidelines of the Declaration of Helsinki, and approved on 2/8/2017 by the Ethics Committee of Azienda USL Valle d'Aosta-Unité Sanitaire Locale Vallée d'Aoste protocol code n. 907.

Informed Consent Statement: Informed consent was obtained from all subjects involved in the study.

Data Availability Statement: Data sharing not applicable.

Acknowledgments: This is dedicated to Piero Ettore Quirico (1952-2018) for his teachings.

Conflicts of Interest: The authors declare no potential conflicts of interest with respect to the research, authorship and/or publication of this article.

\section{References}

1. Imray, C. Acute Mountain Sickness: Pathophysiology, Prevention, and Treatment. Prog. Cardiovasc. Dis. 2010, 52, 467-484. [CrossRef] [PubMed]

2. Ainslie, P.N.; Subudhi, A.W. Cerebral blood flow at high altitude. High Alt. Med. Biol. 2014, 15, 133-140. [CrossRef]

3. Willie, C.K.; Macleod, D.B.; Shaw, A.D.; Smith, K.J.; Tzeng, Y.C.; Eves, N.D.; Ikeda, K.; Graham, J.; Lewis, N.C.; Day, T.A.; et al. Regional brain blood flow in man during acute changes in arterial blood gases. J. Physiol. 2012, 590, 3261-3275. [CrossRef] [PubMed]

4. Willie, C.K.; Smith, K.J.; Day, T.A.; Ray, L.A.; Lewis, N.C.; Bakker, A.; Macleod, D.B.; Ainslie, P.N. Regional cerebral blood flow in humans at high altitude: Gradual ascent and two weeks at 5050 m. J. Appl. Physiol. 2014, 116, 905-910. [CrossRef] [PubMed]

5. Berré, J. Cerebral blood flow velocity responses to hypoxia in subjects who are susceptible to high-altitude pulmonary oedema. Eur. J. Appl. Physiol. Occup. Physiol. 1999, 80, 260-263. [CrossRef] [PubMed]

6. Baumgartner, R.W. Enhanced cerebral blood flow in Acute Mountain Sickness. Aviat. Space Environ. Med. 1994, 65, 726-729. [PubMed]

7. Baumgartner, R.W. Acute mountain sickness is not related to cerebral blood flow: A decompression chamber study. J. Appl. Physiol. 1999, 86, 1578-1582. [CrossRef]

8. Brugniaux, J.V. Cerebrovascular response to altitude. Respir. Physiol. Neurobiol. 2007, 158, 212-223. [CrossRef]

9. Lucas, S.J. Alterations in cerebral blood flow and cerebrovascular reactivity during 14 days at $5050 \mathrm{~m}$. J. Physiol. 2011, 589, 741-753. [CrossRef]

10. Bian, S.Z. Cerebral hemodynamic characteristic of acute mountain sickness upon acute high altitude exposure at $3700 \mathrm{~m}$ in young Chinese men. Eur. J. Appl. Physiol. 2014, 114, 2193-2200. [CrossRef]

11. Sagoo, R.S.; Hutchinson, C.E.; Wright, A.; Handford, C.; Parsons, H.; Sherwood, V.; Wayte, S.; Nagaraja, S.; Ng'Andwe, E.; Wilson, M.H.; et al. Magnetic resonance investigation into the mechanisms involved in the development of high altitude cerebral edema. J. Cereb. Blood Flow Metab. 2017, 37, 319-331. [CrossRef]

12. Hackett, P.H.; Rennie, D.; Levine, H. The incidence, importance, and prophylaxis of acute mountain sickness. Lancet 1976, 2, 1149-1155. [CrossRef] 
13. Roach, R.C. The 2018 Lake Louise Acute Mountain Sickness Score. High Alt. Med. Biol. 2018, 19, 4-6. [CrossRef]

14. Li, Q.Q.; Shi, G.X.; Xu, Q.; Wang, J.; Liu, C.Z.; Wang, L.P. Acupuncture effect and central autonomic regulation. Evid. Based Complement. Altern. Med. 2013, 2013, 267959. [CrossRef] [PubMed]

15. Maciocia, G. The Foundations of Chinese Medicine, 3rd ed.; Churchill Livingstone, Elsevier: Amsterdam, The Netherlands, 2015.

16. Tjen-A-Looi, S.C.; Li, P.; Longhurst, J.C. Medullary substrate and differential cardiovascular responses during stimulation of specific acupoints. Am. J. Physiol. 2004, 287, R852-R862. [CrossRef] [PubMed]

17. Chae, Y. Inserting needles into the body: A meta-analysis of brain activity associated with acupuncture needle stimulation. J. Pain 2013, 14, 215-222. [CrossRef] [PubMed]

18. Langevin, H.M.; Churchill, D.L.; Cipolla, M.J. Mechanical signalling through connective tissue: A mechanism for the therapeutic effect of acupuncture. FASEB J. 2001, 15, 2275-2282. [CrossRef]

19. Wang, G.M. Impacts of Taichong (LR 3) on blood flow velocity in patients with vertebrobasilar insufficiency. Zhongguo Zhen Jiu 2011, 31, 216-218. [PubMed]

20. Lei, L.M. Effects of different acupuncture treatment on mean blood flow velocity of middle cerebral artery on the affected side and rehabilitation of hemiparalysis caused by cerebral infarction. Zhongguo Zhen Jiu 2009, 29, 517-520. [PubMed]

21. Allais, G. Acupuncture in the prophylactic treatment of migraine without aura: A comparison with flunarizine. Headache 2002, 42, 855-861. [CrossRef]

22. Zhou, F. Electroacupuncture and brain protection against cerebral ischemia: Specific effects of acupoints. Evid. Based Complement. Alternat. Med. 2013, 2013, 804397. [CrossRef] [PubMed]

23. Quirico, P.E. Effects of the acupoints PC6 e LR3 on cerebral blood flow in normal subjects and in migraine patients. Neurol. Sci. 2014, 35 (Suppl. 1), S129-S133. [CrossRef] [PubMed]

24. Hori, E.; Takamoto, K.; Urakawa, S.; Ono, T.; Nishijo, H. Effects of acupuncture on the brain hemodynamics. Auton. Neurosci. 2010, 157, 74-80. [CrossRef]

25. Zhao, Z.Q. Neural mechanism underlying acupuncture analgesia. Prog. Neurobiol. 2008, 85, 355-375. [CrossRef] [PubMed]

26. Quirico, P.E.; Pedrali, T. Teaching Atlas of Acupuncture, Volume I: Channels and Points; Thieme: Stuggard, Germany, 2007.

27. Ezzo, J. Cochrane systematic reviews examine PC6 point stimulation for nausea and vomiting. J. Altern Complement. Med. 2006, 12, 489-495. [CrossRef]

28. Lee, A. Stimulation of the wrist acupuncture point PC6 for preventing postoperative nausea and vomiting. Cochrane Database Syst. Rev. 2015, 11, CD003281. [CrossRef]

29. Linde, K.; Allais, G.; Brinkhaus, B.; Manheimer, E.; Vickers, A.; White, A.R. Acupuncture for migraine prophylaxis. Cochrane Database Syst. Rev. 2009, 1, CD001218. [CrossRef]

30. Giovanardi, C.M. Acupuncture vs. Pharmacological Prophylaxis of Migraine: A Systematic Review of Randomized Controlled Trials. Front. Neurol. 2020, 11, 576272. [CrossRef]

31. Basnyat, B. Everest or bust: A cross sectional, epidemiological study of acute mountain sickness at 4243 meters in the Himalayas Aviat. Space Environ. Med. 1999, 70, 867-873. [PubMed]

32. Zhang, J.H.; Cao, X.D.; Lie, J.; Tang, W.J.; Liu, H.Q.; Fenga, X.Y. Neuronal specificity of needling acupoints at same meridian: A control functional magnetic resonance imaging study with electroacupuncture. Acupunct. Electrother Res. 2007, 32, 179-193. [CrossRef]

33. So, E.W.; Ng, E.H.; Wong, Y.Y.; Lau, E.Y.; Yeung, W.S.; Ho, P.C. A randomized double blind comparison of real and placebo acupuncture in IVF treatment. Hum. Reprod. 2009, 24, 341-348. [CrossRef]

34. Manheimer, E. Selecting a control for in vitro fertilization and acupuncture randomized controlled trials (RCTs): How sham controls may unnecessarily complicate the RCT evidence base. Fertil. Steril. 2011, 95, 2456-2461. [CrossRef] [PubMed]

35. Birch, S.; Lee, M.S.; Kim, T.H.; Alraek, T. Historical perspectives on using sham acupuncture in acupuncture clinical trials. Integr. Med. Res. 2022, 11, 100725. [CrossRef] [PubMed]

36. Burtscher, M.; Flatz, M.; Faulhaber, M. Prediction of susceptibility to acute mountain sickness by $\mathrm{SaO}_{2}$ values during short-term exposure to hypoxia. High Alt. Med. Biol. 2004, 5, 335-340. [CrossRef] [PubMed]

37. Rathat, C.; Richalet, J.P.; Herry, J.P.; Larmignat, P. Detection of high-risk subjects for high altitude diseases. Int J. Sports Med. 1992, 13 (Suppl. 1), S76-S78. [CrossRef]

38. Wilson, M.H. Cerebral artery dilatation maintains cerebral oxygenation at extreme altitude and in acute hypoxia-An ultrasound and MRI study. J. Cereb. Blood Flow Metab. 2011, 31, 2019-2029. [CrossRef] [PubMed] 